\title{
THE ROLE OF LEGISLATIONS IN ASSURING TOURISTS' SAFETY (A STUDY OF VIOLENT TOURISTIC CRIMES AFFECTING TOURISTS' SECURITY IN EGYPT- APPLYING ON SHARM EL-SHEIKH AS A TOURIST DESTINATION)
}

\author{
Sabrina Mohamed Ahmed Refaat Abdel-Wahab \\ Lecturer, Tourism Studies Department \\ Faculty of Tourism and Hotels, Alexandria University
}

\begin{abstract}
Touristic crimes vary from several ones mostly including robbery, internet frauds, credit card frauds, physical assaults and terrorism. In the context of this study, the concern of the researcher is with the existence of touristic crimes in Egypt and the absence of effective related laws. Two types of touristic crimes against tourists will be discussed and analyzed; the sexual harassment and terrorism threats.
\end{abstract}

Keywords:touristic crimes- terrorism- sexual harassment-legislations-safety.

\section{Introduction}

The aim of this study is to investigate the touristic crimes in the egyptian legislation. The concern of the researcher is with the existence of touristic crimes in Egypt and the absence of effective related laws. Two types of touristic crimes against tourists have been discussed and analyzed; the violence against tourists that can be obvious in sexual harassment and terrorism threats. The study proved that legislation alone is not enough to maintain safety and security at any tourist destination, and that's why it is necessary to develop some strategies to achieve coordination and integration between all stakeholders concerned to reduce or eliminate the crimes. The study also proved that the Image of Sharm El-Sheikh in regard to safety and security is bad, and not up to the historical or touristic importance of Sharm El-Sheikh. Some recommendations have been introduced in order to solve these issues.

\section{The Study Objectives}

The main objectives of this study are the following;

1. To investigate the extent to which tourists feel secure and safe in Egypt.

2. To reveal whether there are adequate policies and laws that address situations of touristic crimes in Egypt.

3. To investigate the levels to which tourism policies, laws and even acts related to touristic crimes in Egypt, are practiced or implemented.

4. To suggest effective policies and modifications on the Egyptian legislation system related to the touristic crimes.

\section{Touristic Crimes}

Tourism is regarded as a modern day engine of growth and is one of the largest growing industries internationally. A very important factor that might influence tourism demand is 
generally overlooked in the literature: safety of the destination. When individuals decide about whether to take a holiday and where to go (destintion), they would take the risk of victimization into account. Other things equal, people are more likely to visit safer places with no obvious crimes (Duha,2013). Crimes against tourists can affect tourism by significantly damaging a location's image. Therefore, the most important prerequisite for a successful tourist industry is the reputation of having crime under control and guaranteeing tourists' safety (Ronald,2004). Although theft is the most common crime against tourists, they are vulnerable to other crimes as well, including physical and sexual assault, terrorism,internet frauds, credit card fraud, and scams (e.g., being sold "bargain basement" antiques or imitations of expensive watches)(Harper,2001). Growth in tourism, however, has also led to increased opportunities for, and incidences of, crime. Indeed, a long-established relationship exists between increases in crime and demand on tourism; major economic crimes (e.g., robbery, burglary) in some highly popular tourism venues have a "similar season to tourism," for several reasons. First, tourists are lucrative targets, since they are more likely to carry large sums of money and other valuables. Second, tourists are vulnerable because they are typically relaxed and off guard-and sometimes careless- while on vacation. Finally, tourists are often less likely to report crimes or to testify against suspects and assaults, in order to avoid problems or a return trip. So, it can be obvious that tourist crimes can be manifested as one of several scenarios (DeAlbuquerque, 1999):

- The tourist is an accidental victim, in the wrong place at the wrong time,easily targeted.

- The location is conducive to crime, because of its nightlife, hedonistic culture, and myriad potential victims.

- The industry itself provides victims, as tourists are more prone to taking risks while on holiday, and less likely to observe safety precautions.

- Terrorist or other groups might specifically target tourists, singling them out for hostage-taking or even murder.

If a tourist feels threatened or unsafe at a holiday destination, he or she can develop a negative impression of the destination that can be very damaging to the destination's image and so to the tourism industry which can result in the decline of tourism to the area, this can happen in the following ways (Swart,2015):

- Prospective tourists might decide not to visit a specific destination because it has a reputation for having a high crime rate.

- If tourists feel threatened or unsafe at destinations, they are not likely to take part in activities outside their accommodation facilities.

- Tourists who have felt unsafe or threatened are not likely to return to the destination, and they are not likely to recommend this destination to others.

\section{Terrorism Threats Against Tourists}

Link Between Terrorism and Tourism.International terrorism and tourism are paradoxically connected through their mutual characteristics such as both crossing national borders, both involving citizens of different countries, and they both use travel and communications technologies. Tourists are targeted by terrorists because they are seen as outsiders representing a mode of neo-colonialism or a threat to their traditions,social norms and even religious convictions. The link between terrorism and 
tourism reveals that tourism is not only the medium of communication instigated by terrorists but it can be the message also. Tourism can incite socioeconomic, cultural, political or religious resentment as well as being used as a cost effective instrument to deliver a broader message of ideological or political opposition. It is evident that terrorists choose tourists specifically as the symbolism, high profile, and news value of international tourists are too valuable not to exploit (Baker,2014) . The relationship between tourism and terrorism can involve three possible scenarios: Terrorism that is aimed at civil targets yet sometimes victimizes tourists too; terrorism that is directed at economic objectives that are functionally related to tourism; and finally, terrorism that targets not only tourists but tourism as a whole since both are regarded as "soft targets" with relatively high-impact media coverage (Pizam,2005).

\section{Case Study: (Tourism Law in Mozambique "Law 4/2004")}

Bearing in mind that Mozambique has important tourism resources that place it in a favorable and competitive position in the regional and international tourism market, which incumbent upon the State to update the tourism relevant legal instruments. In these terms, under article 135(1) of the Constitution, the Assembly of the Republic determines to establish a legal framework for promoting and carrying out tourism activities, and with a main goal which is to protect tourists and ensure their safety and finally their satisfaction.

The most important aims of this law were, to encourage measures for the safety and tranquility of tourists, consumers of tourism services, and also to ensure equal rights and opportunities for all those subject to this law.

According to law 4/2004, some rights are guaranteed for tourists, such as (http://www.doingbusiness.org,2015):

- To obtain objective, complete and accurate information about each and all of the conditions, prices and facilities offered by suppliers of tourism products and services.

- To enjoy tourism products and services offered on the conditions and at the prices agreed upon.

- To obtain documents that confirm the contractual terms and the agreed prices.

- To enjoyprivacy, tranquility, personal security and safety of their property.

- To report grievances and make complaints about the supply of tourism services or products according to the law, and to obtain opportune and adequate responses.

- To enjoy tourism services in good conditions of cleanliness and hygiene.

- To obtain proper information about the country for the prevention of accidents and contagious diseases.

In this case study we can see how far the decision makers were intelligent enough to pay a lot of attention for tourists' security and safety, which reflect their awareness of the importance of this issue. All that resulted in a comprehensive and effective law to protect tourists and to ensure their safety and satisfaction (as it also includes anyone who does not fit the definition of a tourist but uses tourist services and facilities).

\section{Case Study Of South African Perceptions And Interventions On Crime Against Tourists (Nkosi,2010-Perry,2013)}

South Africa has developed a reputation for being an unsafe destination and has been labeled the 'crime capital of the world', South African Police Services statistics suggest 
that crime in the country increased from 1985. This began to change in 1996 when most categories of crime showed stabilization. Despite this trend, current levels of crime remain high and continue to breed insecurity in the country. Crimes have severe implications through the costs of victimization which undermine socio-economic development. Also, fear of crime often changes lifestyles, negatively affect the life quality. (http://alternation.ukzn.ac.za/Files/docs/17.2/09\%20Swa\%20FIN.pdf,2015).

In South Africa, tourists have been exposed to criminal attacks. This harms the tourists as individuals physically and emotionally. By time this goes to an extent where even the family and friends of these particular tourists are affected by the criminal act committed against the tourist. This occurs when criminal attacks such as rape, terrorism and murder are committed. The South African government is committed to ensuring the security and safety of all tourists whether they are domestic or international tourists. Policy guidelines to protect and ensure tourist security and safety have been formulated to be implemented in all provinces.

The strategy that has been devised has short and long term strategies and actions to reduce crimes and violence against tourists. This strategy will be implemented in collaboration with other relevant organizations such as the South African Police Services (SAPS), Traders Against Crime (TAC), Community Police Forums (CPF's), Criminal Justice System (CIS) and many other relevant stakeholders who are interested in ensuring tourists' security and safety at any destination in South Africa. It has been agreed that tourists should also be provided with adequate information or tips that will help them to improve their security and safety.

\section{ProposedModel(http://www.restaurant.org.za/pdf/Tourism_Safety_\&_Support_Strat_Framewo rk_WC.pdf,2015):}

This strategy has been formulated for the Western Cape and was aligned to the National Guideline regarding Tourism Safety. Key learnings were derived from a comprehensive manual of the World Tourism Organization: Tourist Safety and Security, Practical Measures for Destinations. It has been recognized that no single agency can prevent crimes, promote security and safety or empower victims of crime. Each network of service providers in the system has a specific role to play. The forum promotes a partnership approach to local crime prevention and incident management, involving:

- Department of Tourism;

- Tourism agencies;

- SAPS, traffic and municipal police (local police);

- Judiciary authorities;

- Emergency services (ambulance and fire department);

- Health and social development services;

- Transport sector;

- Airports Company;

- Business (retail, services and commercial industry);

- Local communities;

- Non-governmental organizations (NGO'S).

Tourism Safety Centre is established, to work side by side with the Local Tourist

Information Centre. This centre should have a management team, made up of relevant 
stakeholders and role-players and be led by a full time staff and coordinator, as determined by the management team. The partners should agree to a business plan with a shared vision, strategic goals and preferred outcomes. It is recommended that a strategic facilitator must be appointed to conduct a number of workshops to develop a framework for the following issues, which should be incorporated into the initial plan.

Figure1.Tourism Safety centre

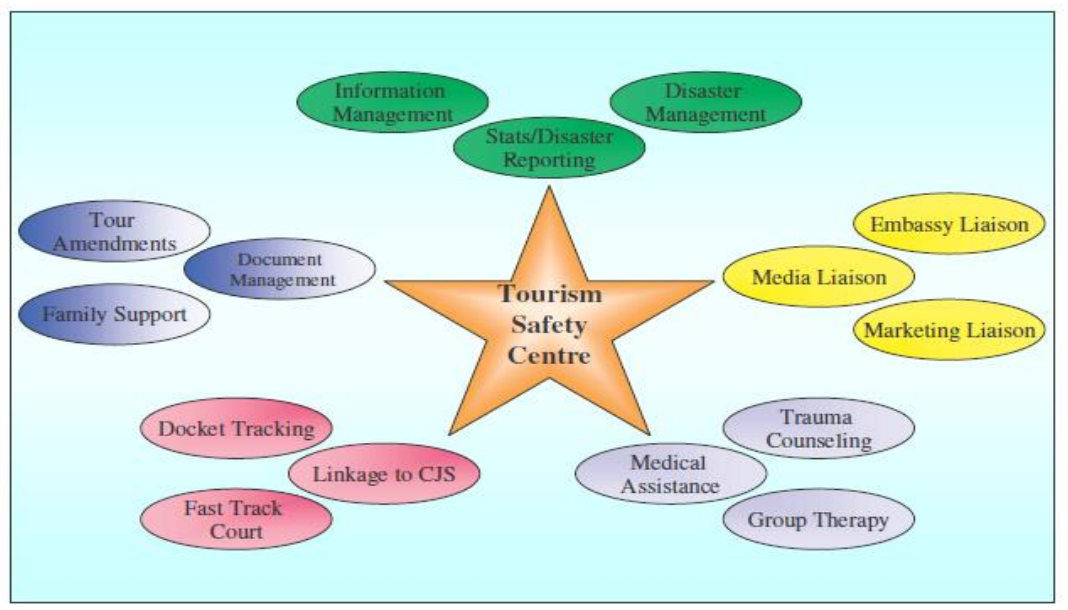

Partners to the Integrated Model

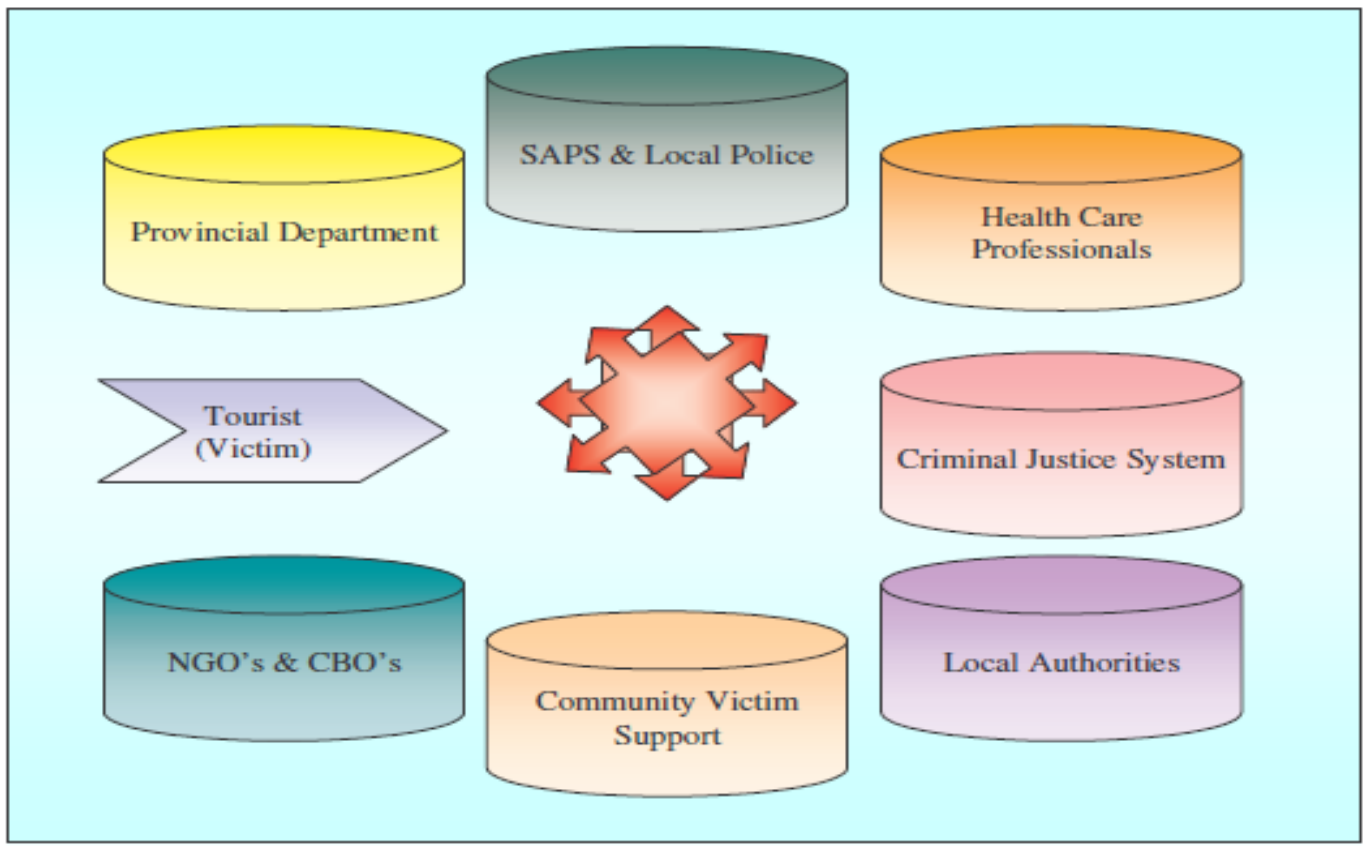

Source:

(http://www.restaurant.org.za/pdf/Tourism_Safety_\&_Support_Strat_Framework_WC.pd $\underline{\mathrm{f}, 2015)}$ 


\section{Role of TheProvincial Department}

The department should continue to chair the forum and should co-ordinate the function of the task team. Furthermore, it should:

- Inform local stakeholders and local role players of the initiative and to recruit members to management team.

- Facilitate a partnership agreement with other role players and ensure that different roles and responsibilities are understood.

- Facilitate special training and the development of protocols where role players may need to develop skills to best serve the targets of the initiative.

- Manage the flow of information to the public and specifically to tourists, so that they are equipped to take safety and security precautions.

- Maintain response networks and mobilize role players when there is an incident of any crime involving tourists.

- Ensure that appropriate referrals are made where for instance a translator is needed or travel documents must be replaced.

- Ensure that the victim has access to transport and accommodation where and when necessary.

- Manage communications pertaining to an incident involving a tourist so as to minimize the negative impacts of such an incident, for both the tourist and the local tourism industry.

- Be the liaison between different national departments, Tourism and Foreign Affairs where their intervention is sought.

\section{Role of Police}

SAPS should have designated officers responsible for Safety at local level. Furthermore, it should:

- Provide information from time to time regarding crime trends and patterns as they may impact tourist safety and security at local levels.

- Alert the (Task Team) when there is a particular threat to tourist safety.

- Be available and standby to respond with urgency to an incident involving a tourist.

- Ensure that a victim is treated with respect and dignity at any time, is offered information and the opportunity to provide information regarding the incident and that the victim is protected from further harm.

- Ensure that the victim is referred for health care and counseling where and when required.

- Ensure that where possible the incident is handled with expediency and that no unnecessary delays are allowed in the processing of the incident.

- Work with the (Task Team) to create a safe environment for tourists.

- Assist in the communication of safety issues and to follow communication protocols as agreed by the (Task Team) where there is an incident or a crime involving a tourist.

\section{Community Based Victim Support}

A representative should be a coordinator of the program in the area. Furthermore, it should: 
- Contribute through knowledge of local victimization trends, any information that might assist in making the area safer for tourists.

- Facilitate the availability of a trained volunteer who has special knowledge of tourist needs, to counsel and offer special support and assistance to a victim following an incident.

- Follow communication protocols undertaken after the incident.

- Ensure effective liaison with the criminal justice system following an incident, and that the victim (the tourist) understands what is happening and what will happen.

- Ensure that the tourist is aware of the rights of victims of crime and that he or she is empowered to access those rights (to respect and dignity, to offer information, to receive information, to legal advice and to be protected from further victimization).

- Facilitate ongoing liaison with the victim once he has returned home, should the need arise.

The previous case study shows that the legislative environment alone is not enough to achieve the security of the tourist in the destination, but this legislation should be supported by security strategies include the participation of all stakeholders, not only to deal with the various crimes committed against tourists, but to prevent these crimes, or at least limit them.

\section{Touristic Crimes and Security Situation in Egypt}

The removal of President Mohamed Morsy in July 2013 sparked a shift in the pattern of street violence that had marked the security and safety environment from January 2011 to July 2013. Before July 2013, demonstrations frequently were conducted by a range of actors representing various causes. In some cases, it was revolutionaries dissatisfied with the progress since Hosni Mubarak stepped down, liberals or secularists outraged over the new Muslim Brotherhood (MB) government, soccer hooligans with a history of violence directed at police, or even street thugs possibly compensated for creating instability in the country (Egypt 2014 Crime and Safety Report,2014). Crimes in Cairo were moderate but that was not the case in other cities. Since January 2011, the frequency of crime affecting the expatriate community (such as tourists) appears to be increasing. This trend has elevated the concern of the expatriate community that once moved about with little concern for their safety.

\section{Sexual Harassment Against Tourists}

However, there are numerous reports of harassment perpetrated by local males against western females. These incidents run the gamut from lewd comments and gestures to more explicit indecent exposures, inappropriate physical contacts, and sexual harassment. A number of women, to include foreigners, have reported being sexually assaulted in taxis, in public areas and while transiting crowded protest places. Conservatively-attired Egyptian women experience the same gender-based assault. The majority of these incidents occur in the streets of busy cities, but sexual harassments by maintenance workers or delivery persons have also been reported inside private residences.

The government has been ineffective in addressing or rather in dismissing this phenomenon in Egypt. After every similar sexual assaults incidents, the government issues statements condemning the actions and promising prompt effective assessment and solutions for the sexual harassment's problems in Egypt. Although there were many 
attempts by the government to address the problem, none of them have come in active effect (Ebaid,2013).

Generally, sexual harassment is not directly and clearly addressed in the Egyptian Law or constitution; yet, it can be obliquely addressed under three different articles on the Egyptian criminal law. First, in the Article 306 of the Egyptian penal code about "Insulting", only verbal sexual harassment can be entitled as it is considered one type of insulting. Second, sexual harassment can be considered as a "public indecency" and can be entitled to a criminal court and a sentence up to three years under the sexual crimes' section of Article 278 of the penal code. Last but not least, physical and sexual harassment can be included under the Sexual Assault law under Article 268 of the penal code and its trialed under a criminal law as well, but with a longer sentence that ranges between three and fifteen years imprisonment. Although sexual harassment acts could be punished under all the previously mentioned laws and that it has been a bad phenomenon that is noticeably found in the Egyptian society, there were no records of sexual harassment cases that were sent to court except one case in 2008. This refers to four problems concerning those laws: firstly that they are weak and implicitly addressed, secondly that there are constrains in accessing those laws, thirdly that there is a lack of enforcement for these laws, and finally that there is a lack of awareness between people (Ebaid,2013).

Based on that, there's a bad image about Egypt regarding the tourism and sexual harassment issues, and that can be concluded obviously in the last report of "Egypt 2014 Crime and Safety Report", issued by the bureau of diplomatic security, U.S. department of state, in March 2014. In this report there was a topic titled "Tips on How to Avoid Becoming a Victim" for female tourists, which indicated the following: "Foreign women are advised to dress modestly when going out in public, which includes covering their legs and shoulders and avoiding garments that are tight or otherwise revealing. Women and teenage girls should avoid walking the streets alone after dark, and if they must be out, should not be alone. Additionally, they should be very careful with public transportation and should always sit in the back seat of the taxi and refrain from engaging in conversation, beyond basic pleasantries, with the driver"( Egypt 2014 Crime and Safety Report,2014).

\section{Terrorism in Egypt}

Prior to October 2004 attack, there had been no terrorist incidents involving tourists in Egypt since the mid-1990s. In 2004, 2005, and 2006 several attacks were directed to tourist locations along the Red Sea. Egypt has experienced several terrorist incidents over the past few years, and the threat of terrorist attacks outside of the Sinai Peninsula - a historic hotbed of activity - is now increasing. While not specifically targeted Americans, these bombing attacks resulted in the death of numerous Egyptian nationals and foreign tourists, including Americans, and prompted an increased security presence by Egyptian Security forces. In February 2009, a small bomb exploded in the main square in front of the Khan El-Khalili bazaar in Cairo, causing many casualties among foreign visitors, including the death of a French tourist. A second explosive device at the bazaar was discovered and detonated by police. On December 31, 2010, a bombing attack occurred in Alexandria at a Coptic church, resulting in a reported 27 deaths and 200 injuries. The victims were from both the Christian and Muslim communities. In September 2012, 
Egyptian authorities arrested members of a terrorist network in Cairo who may have been seeking to carry out attacks against government institutions and Western interests (Egypt 2014 Crime and Safety Report, 2014).

More recently, the Sinai-based extremist group, AnsarBayt al-Maqdis (ABM) has claimed its responsibility for a number of terrorist attacks in Cairo, demonstrating an ability to operate beyond the Sinai. ABM has primarily targeted police and police facilities, carrying out large-scale suicide bombing attacks against the police headquarters in downtown Cairo and in Mansoura, as well as several smaller bombing operations, including one directed at a police station in Dokki. In addition, ABM has claimed responsibility for the attempted car bombing assassination of the Minister of Interior in October 2013 and the killing of a senior MOI official in January 2014. ABM has demonstrated sophistication in planning and capacity. It claimed responsibility for two RPGs fired at a cargo ship in the Suez Canal and the downing of an Egyptian military helicopter by a surface-to-air missile in the Sinai. In February 2014, ABM claimed responsibility for the suicide bombing attack of a tourist bus in Taba, near the Israeli border, that killed three South Korean tourists and their Egyptian driver. This attack suggested the possibility that ABM could be shifting its focus from police to economic important goals, such as tourism. The group had mainly focused on cross border attacks into Israel and had been responsible for multiple bombings of Egypt's gas pipeline in the Sinai. ABM has not specifically threatened U.S. citizens but has possibly (through an unconfirmed social media account) indicated that tourists are considered targets.

Moreover, Egypt was ranked as last (128) in terms of security and safety on the World Economic Forum's 2014 Travel and Tourism Competitiveness Index (Schwab,2014).

\section{Egypt's Anti-Terrorism Legislation}

Egypt introduced terrorism as a crime in its penal code by virtue of law no. 97 for the year 1992. A little over 10 years later, the government announced that it was preparing antiterrorism legislation as follow:

Anti-Terrorism Law 2013.The Egyptian government approved a new anti-terrorism law in response to an attack on Cairo University. The law targets to the deter recent escalation of terrorist violence in Egypt. Included in the amendments to the law are provisions increasing the penalties for those acts deemed as "terrorist acts" as well as provisions broadening the scope of the law itself. These reportedly include the death penalty for those found guilty of terrorism and strengthen the punishments for those who promote terrorist acts (http://jurist.org/paperchase/2014/04/egypt-approves-new-antiterror-law.php,2015).

"Terrorist Entity" Law No. 82015 (http://www.middleeasteye.net/news/sisiofficially-approves-egypt-s-anti-terrorist-law-1284094471,2015),(http://www.almonitor.com/pulse/originals/2015/03/egypt-sisi-anti-terrorism-lawopposition.html\#,2015)

Egyptian President Abdel-Fattah al-Sisi signed off on an anti-terrorism law that gives authorities more sweeping powers to ban groups on charges ranging from harming national unity and security to disrupting public order.

According to the Gazette, the law enables authorities to act against any individual or group deemed a threat to national security, including people who disrupt public transportation, it also includes an apparent reference to protests. 
The law consists of 10 articles. Article 1 defines a "terrorist entity" and a "terrorist person," and tackles the source of money, financing and the freezing of funds belonging to terrorists. The other articles specify the authorities tasked with drawing up a list of terrorist entities and the parties entitled to appeal their listing.

The law stipulates that terrorist entities can be "any association, organization, group, or gang that attempts to, aims to, or calls for destabilizing public order; endangers the wellbeing or safety of society; harms individuals or terrorizes them, or endangers their lives or freedoms or rights or safety."

The law stipulates that any group designated as terrorist would be dissolved. It also allows for the freezing of assets belonging to the group, its members and financiers.

In short, there is in Egypt an existence of laws against domestic violence, sexual assault or rape, and sexual harassment. However, there are several problems concerning those laws: they are weak and in so far as they implicitly address the problem, recourse under those laws and to those laws is inaccessible, there is a lack of enforcement for these laws, and finally, there is a lack of awareness on the part of the executive authorities regarding how to deal with this threatening phenomenon (Ebaid, 2013).

\section{Methodology}

Questionnaires were used as a form of collecting data. Closed-ended questions were used in the questionnaire, to gather information. Data analysis was accomplished through using the Statistical Package for the Social Science (SPSS) computer technique. In other instances, statistics and crime records of previous years as well as how criminal activities were overcome would be acquired and put into use.

Sampling. It is understood that the researcher would not be able to access the entire population that is being investigated or observe every event associated with tourism crime in the study area. The research population from which data were to be collected was determined, as well as the stratified random sampling technique used as a point of departure. Since the population consisted of a huge number of tourists, a related sample of about (240) tourists was selected from tourists who visited Sharm el-Sheikh. (60)printed questionnaires were distributed at touristic sites in Sharm El-Sheikh, and all of them have been filled in and collected. (180) online questionnaires were distributed, and only (149) responses have been received.

Pilot Study. Researcher supplied a set of five (10) questionnaires to respondents to test the level of comprehensibility and the consistency of the questions used in the questionnaire. The outcomes of the pilot study were very positive; they did not reveal any negative effects on the exercise. The respondents seemed to clearly understand what was solicited by the questionnaires.

Study Hypotheses. This study assumes the following:

1. Legislation alone is not enough to maintain safety and security at any tourist destination.

2. The Image of "Sharm el-Sheikh" in regard to safety and security is bad.

Questionnaire Analysis. By using SPSS application, questionnaire consistency and reliability has been measured, and the result was as follows: 


\begin{tabular}{|c|c|c|}
\hline Cronbach's Alpha & $\begin{array}{c}\text { Cronbach's Alpha Based } \\
\text { on Standardized Items }\end{array}$ & No of Items \\
\hline $\mathbf{8 3 5}$ & .836 & 209 \\
\hline
\end{tabular}

According to the above table, the questionnaire has a good internal consistency, with Cronbach alpha coefficient of (.835).

Item-Total Statistics

\begin{tabular}{|c|c|c|c|c|c|}
\hline & $\begin{array}{l}\text { Scale Mean if } \\
\text { Item Deleted }\end{array}$ & $\begin{array}{c}\text { Scale } \\
\text { Variance if } \\
\text { Item Deleted }\end{array}$ & $\begin{array}{l}\text { Corrected } \\
\text { Item-Total } \\
\text { Correlation }\end{array}$ & $\begin{array}{c}\text { Squared } \\
\text { Multiple } \\
\text { Correlation }\end{array}$ & $\begin{array}{c}\text { Cronbach's } \\
\text { Alpha if Item } \\
\text { Deleted }\end{array}$ \\
\hline Ques1 & 8.7611 & 2.297 & .660 & 1.000 & .715 \\
\hline Ques2 & 7.6454 & 2.658 & .587 & 1.000 & .658 \\
\hline Ques3 & 7.6587 & 2.475 & .658 & 1.000 & .878 \\
\hline Ques4 & 8.2487 & 2.698 & .457 & 1.000 & .698 \\
\hline Ques5 & 7.2547 & 2.365 & .784 & 1.000 & .587 \\
\hline Ques6 & 8.3547 & 2.476 & .611 & 1.000 & .698 \\
\hline Ques7 & 7.6655 & 2.146 & .578 & 1.000 & .478 \\
\hline Ques8 & 7.6658 & 2.450 & .574 & 1.000 & .321 \\
\hline Ques9 & 7.3254 & 2.254 & .698 & 1.000 & .658 \\
\hline Ques10 & 7.3658 & 2.696 & .687 & 1.000 & .674 \\
\hline Ques11 & 8.5874 & 2.159 & .588 & 1.000 & .125 \\
\hline Ques12 & 7.3254 & 2.951 & .365 & 1.000 & .147 \\
\hline Ques13 & 8.6987 & 2.487 & .547 & 1.000 & .977 \\
\hline Ques14 & 8.6448 & 2.358 & .687 & 1.000 & .654 \\
\hline Total & 8.2654 & 2.254 & 1.000 & 1.000 & .835 \\
\hline
\end{tabular}


According to the above correlation coefficients, the questionnaire is reliable. It has an acceptable internal consistency, and it is statistically significant. Thus, the questionnaire is valid to be applied on research's sample.

The responses analysis was as follows:

\section{Gender}

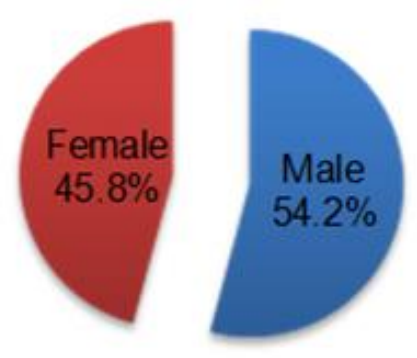

Almost the male respondents were equal to the female respondents, with (54.2\%) male, and $(45.8 \%)$ female.

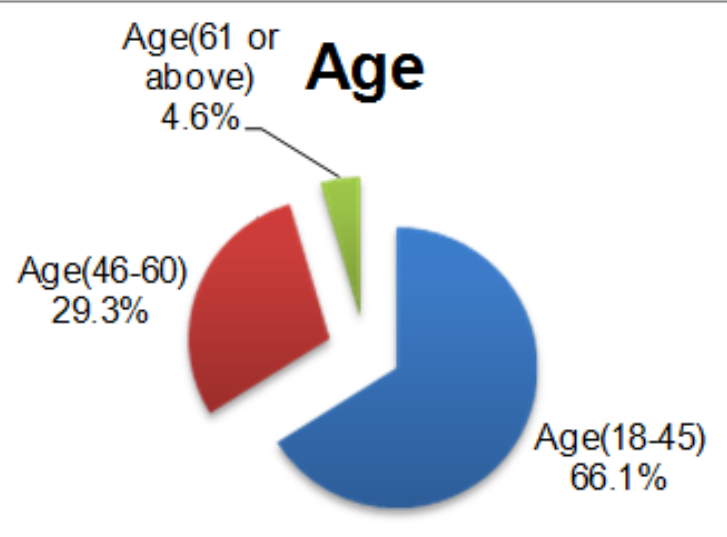

The age range of the majority of respondents was (18-45), with (66.1\%). 


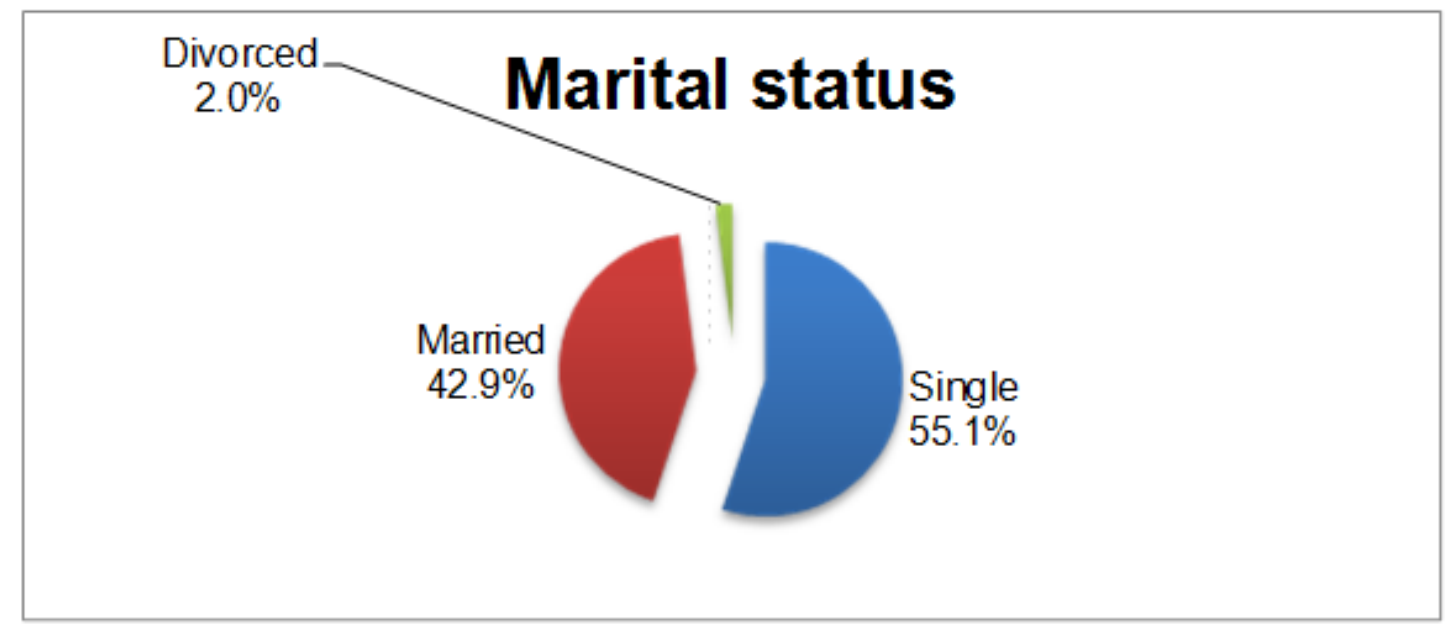

Almost the single respondents were equal to the married respondents, with $(55.1 \%)$ single, and (42.9\%) married.

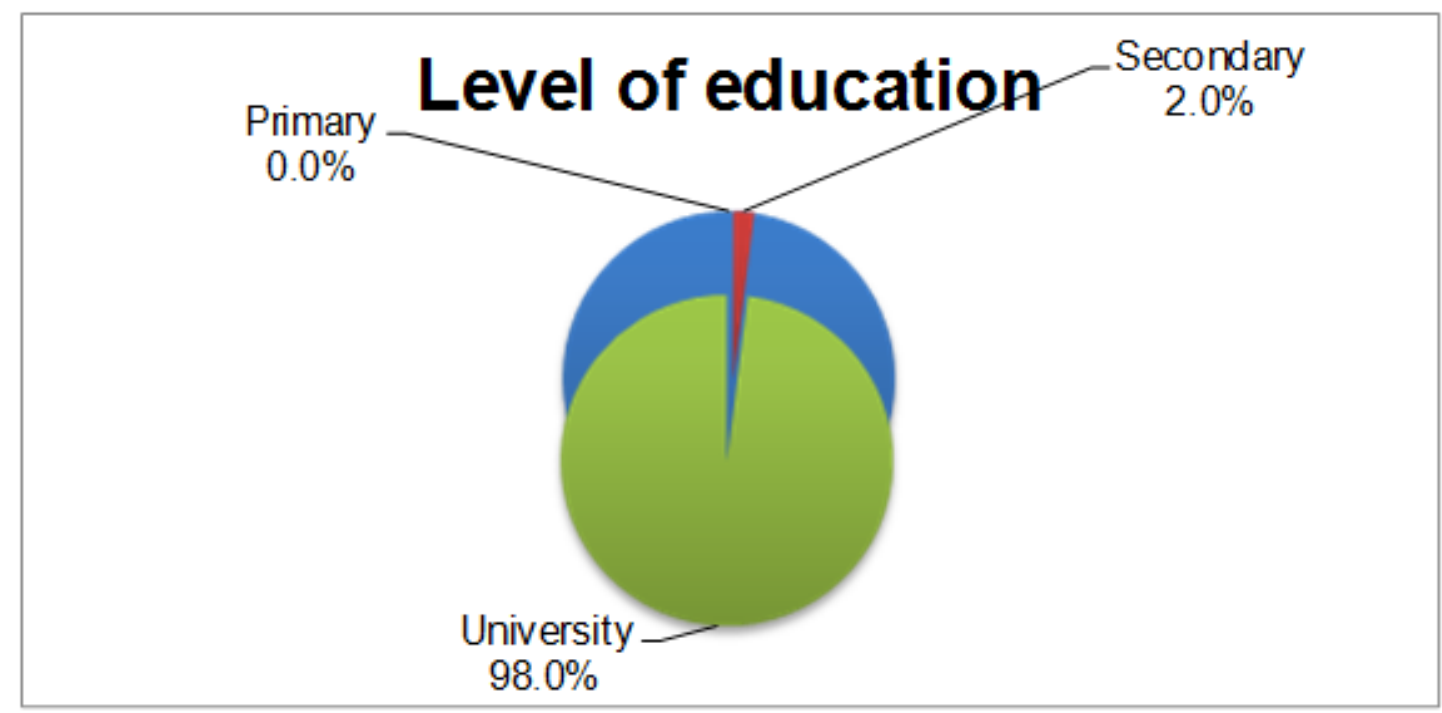

All respondents $(98 \%)$ were either at university level, or have a university degree, with a minority of $(2 \%)$ in secondary level. 


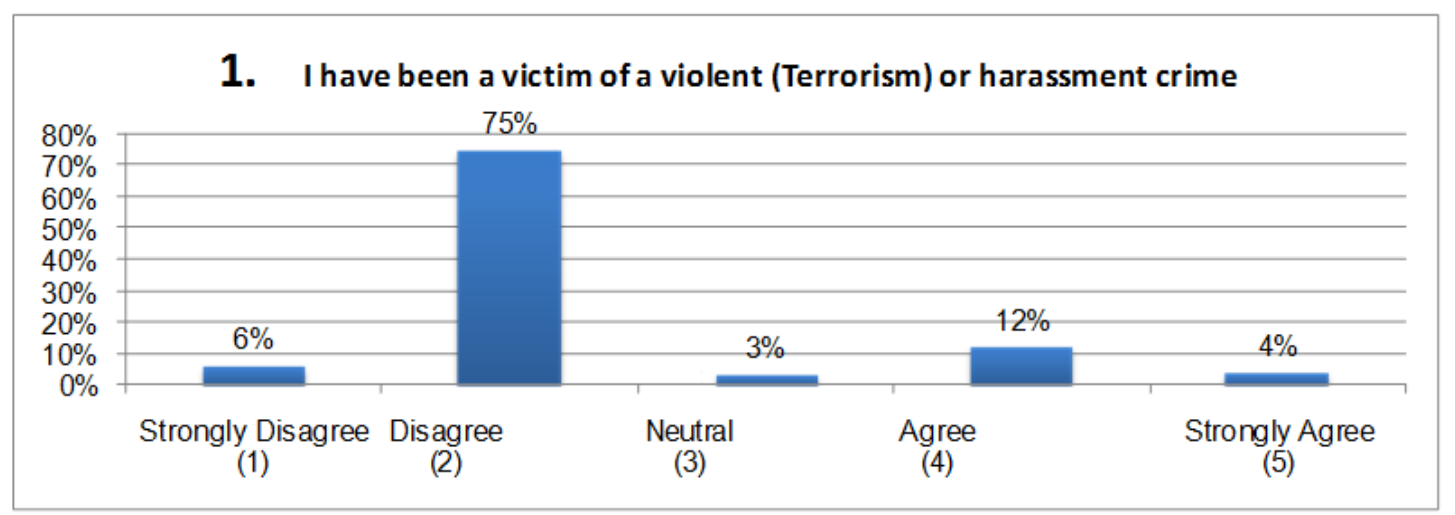

The majority of respondents denied that they have been a victim of a violent or harassment crime with (81\%), and only (16\%) agreed that they have been a victim of such crime.

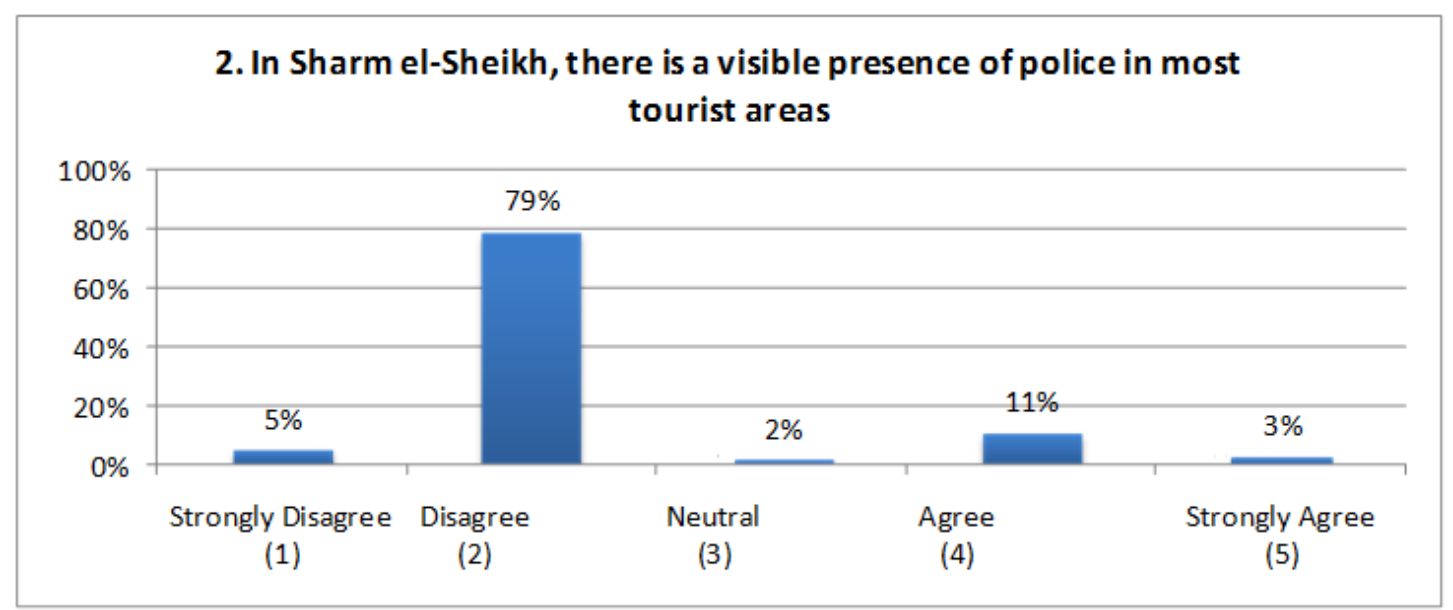

Many respondents (84\%) disagreed that in Sharm el-Sheikh, there is a visible presence of police in most tourists areas, and only (14\%) agreed with that. 


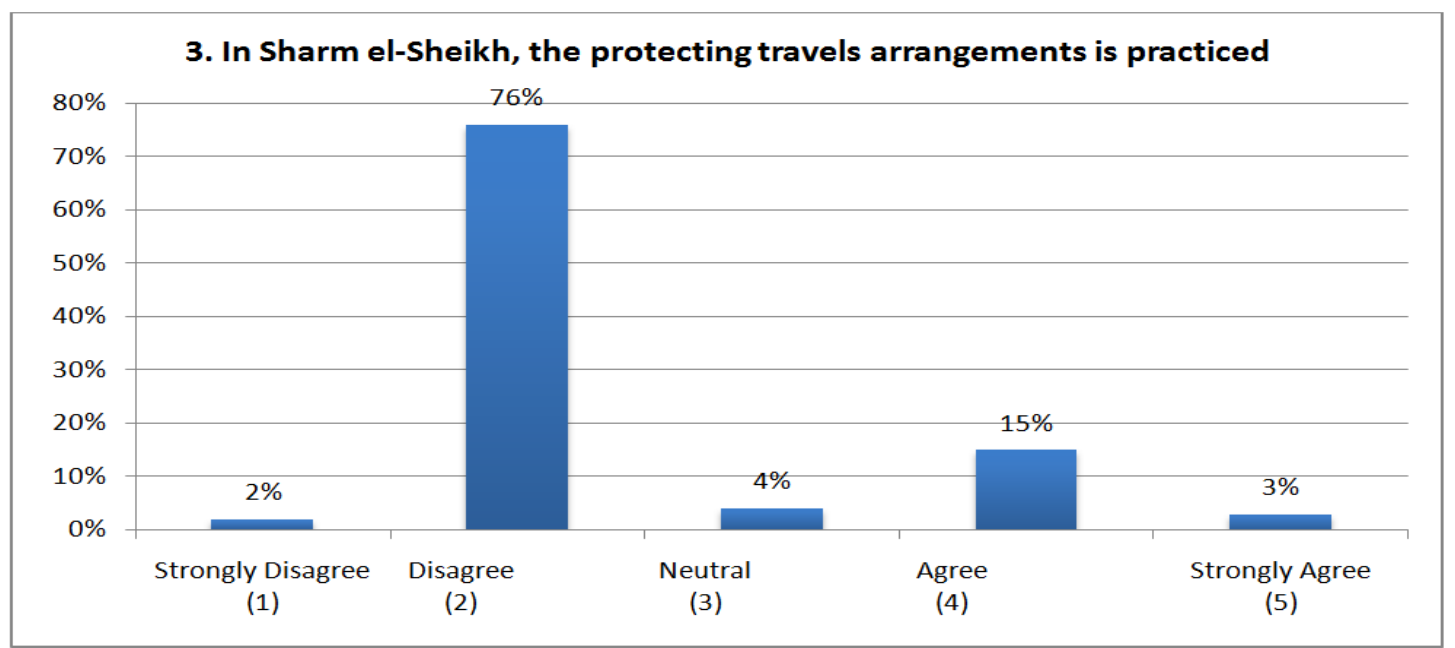

(78\%) of the respondents disagreed that in Sharm el-Sheikh, the protecting travels arrangements is practiced and only (18\%) agreed with that.

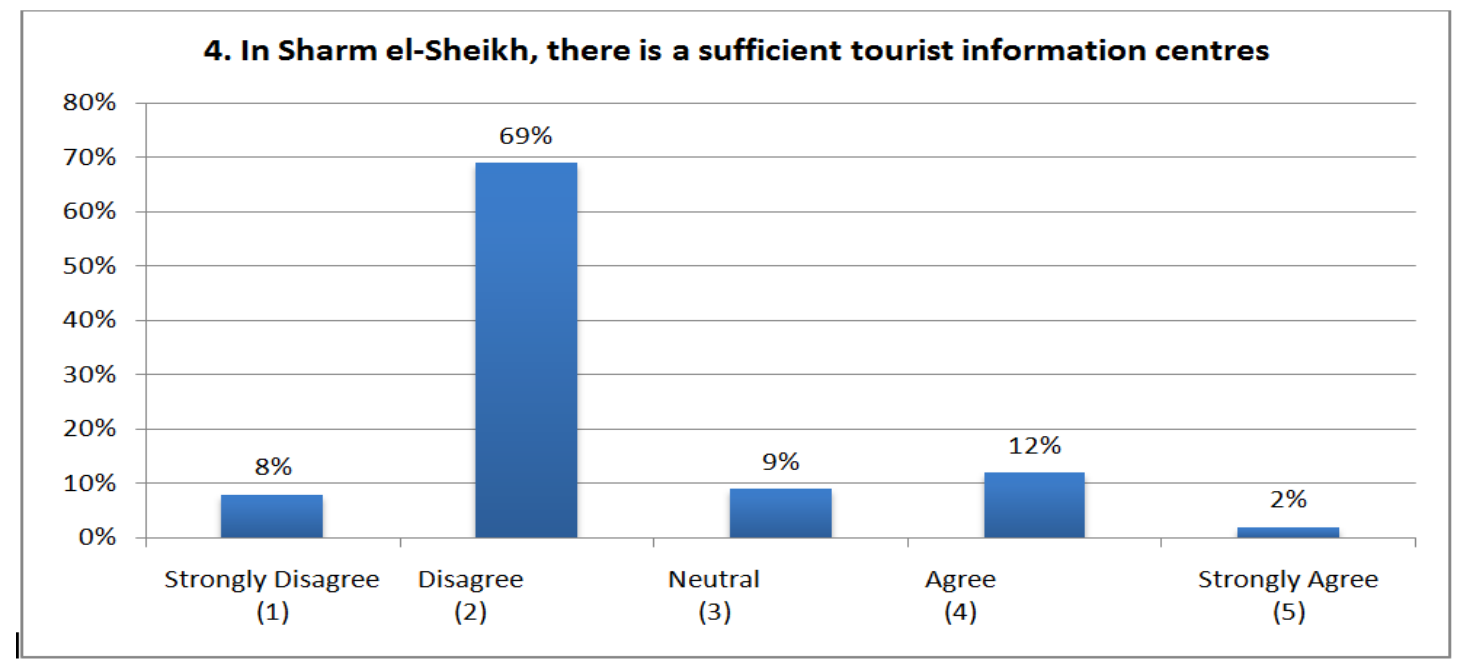

The majority (77\%) of the respondents disagreed that in Sharm el-Sheikh, there's a sufficient tourist information centers, and only (14\%) agreed with that. 


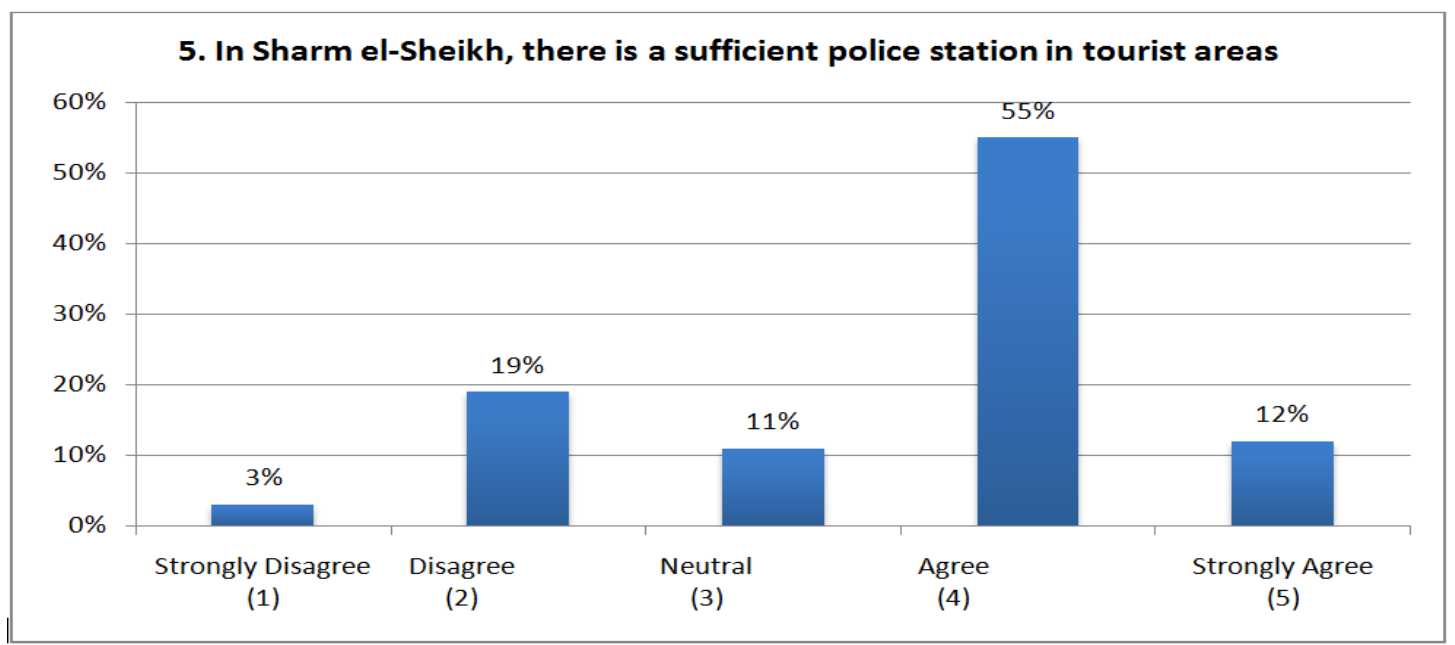

(67\%) of the respondents agreed that in Sharm el-Sheikh, there's a sufficient police station in tourist areas, and only $(22 \%)$ disagreed with that.

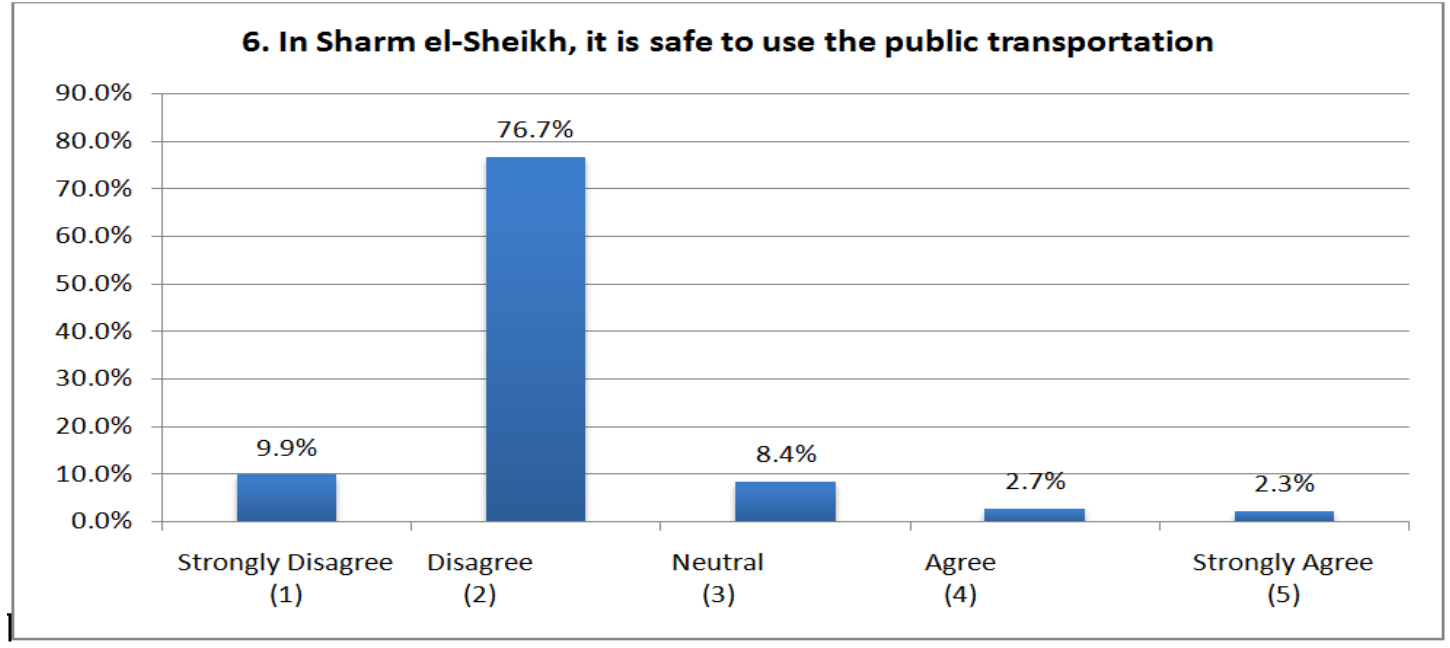

$(86.6 \%)$ of the respondents disagreed that in Sharm el-Sheikh, it is safe to use the public transportation. Only (5\%) agreed with that. 


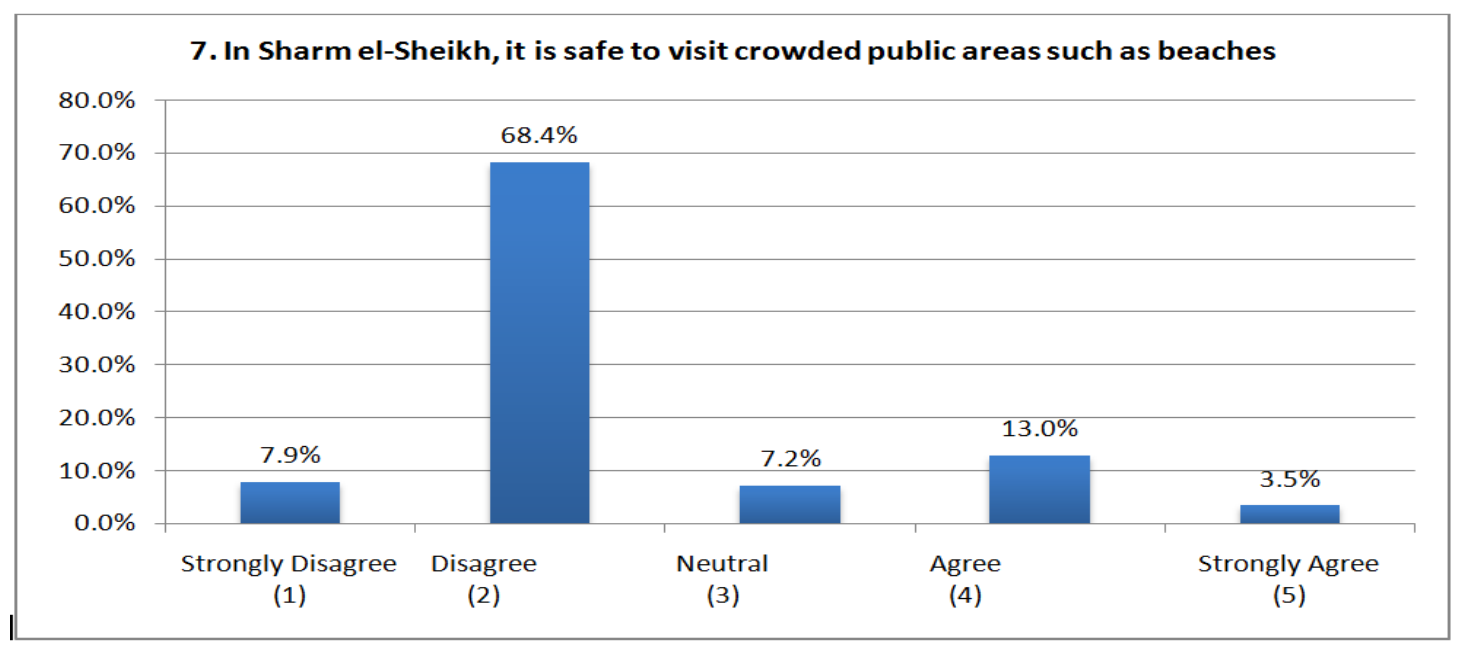

(76.3\%) of the respondents disagreed that in Sharm el-Sheikh, it is safe to visit crowded public areas, and only (16.5\%) agreed with that.

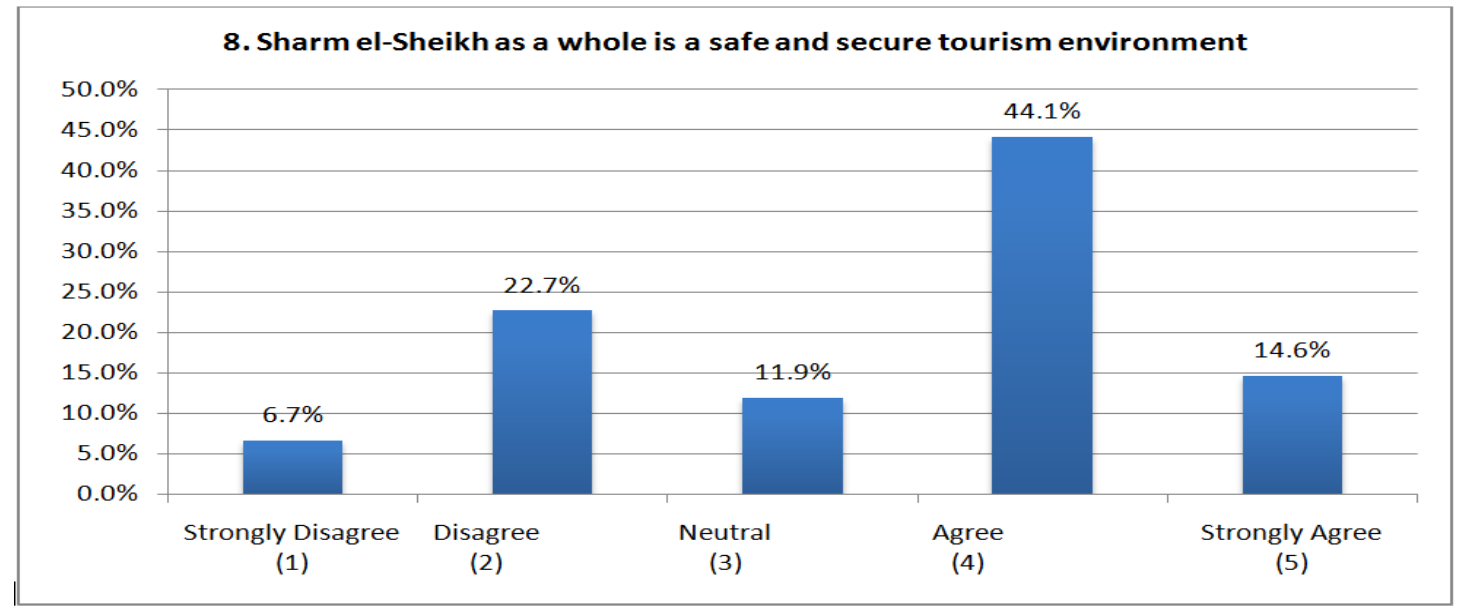

(58.7\%) agreed that Sharm el-Sheikh as a whole is a safe and secure tourism environment. Also many respondents $(29.4 \%)$ disagreed with that. 


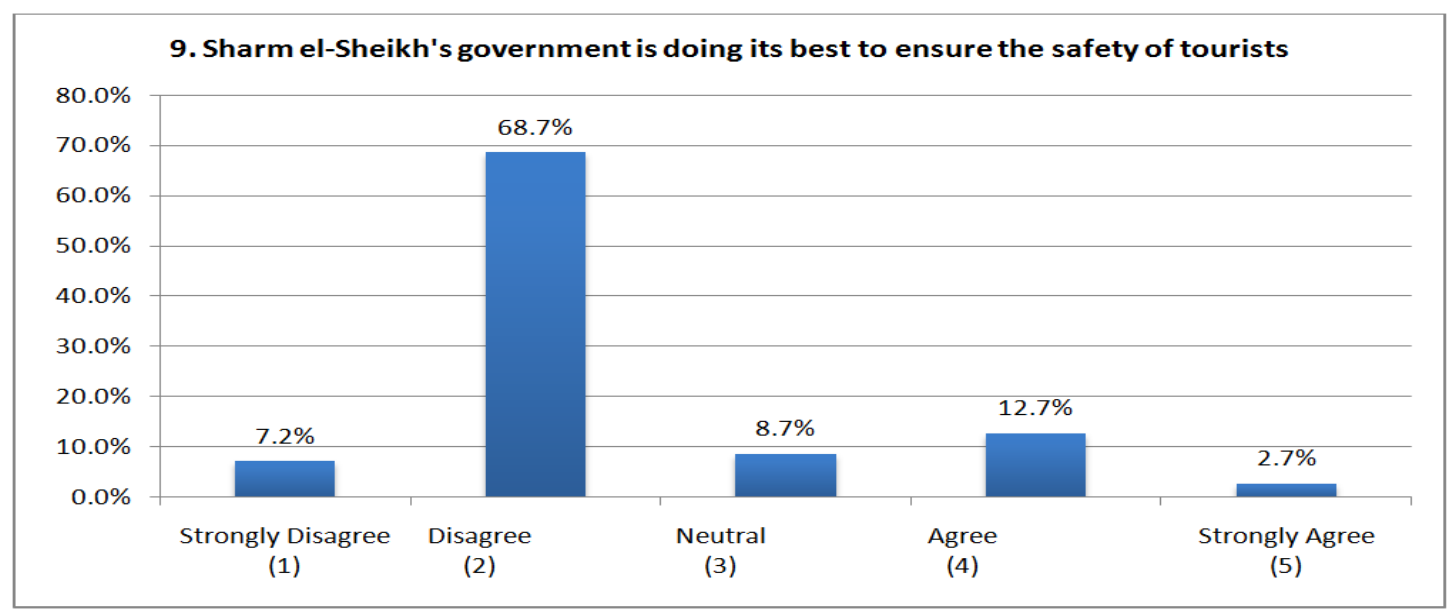

The majority $(75.9 \%)$ of the respondents disagreed that Sharm el-Sheikh's government is doing its best to ensure the safety of tourists, and only (15.4\%) agreed on that.

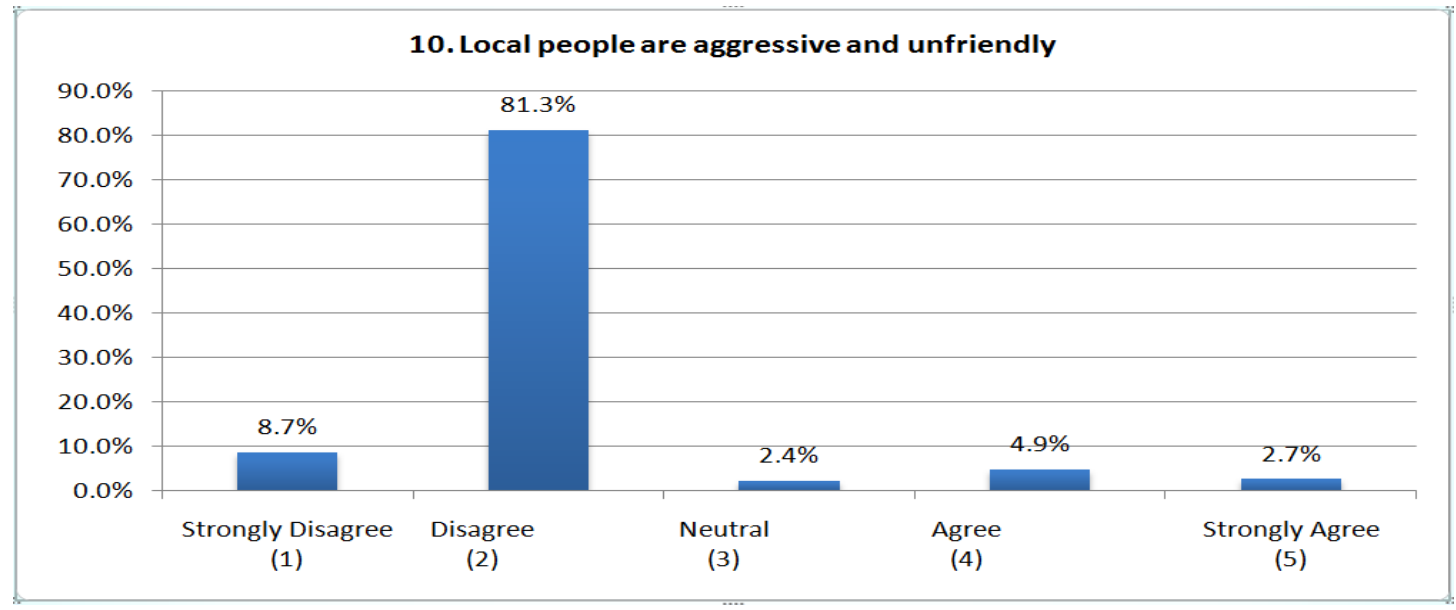

The majority (90\%) disagreed that local people are aggressive or unfriendly.

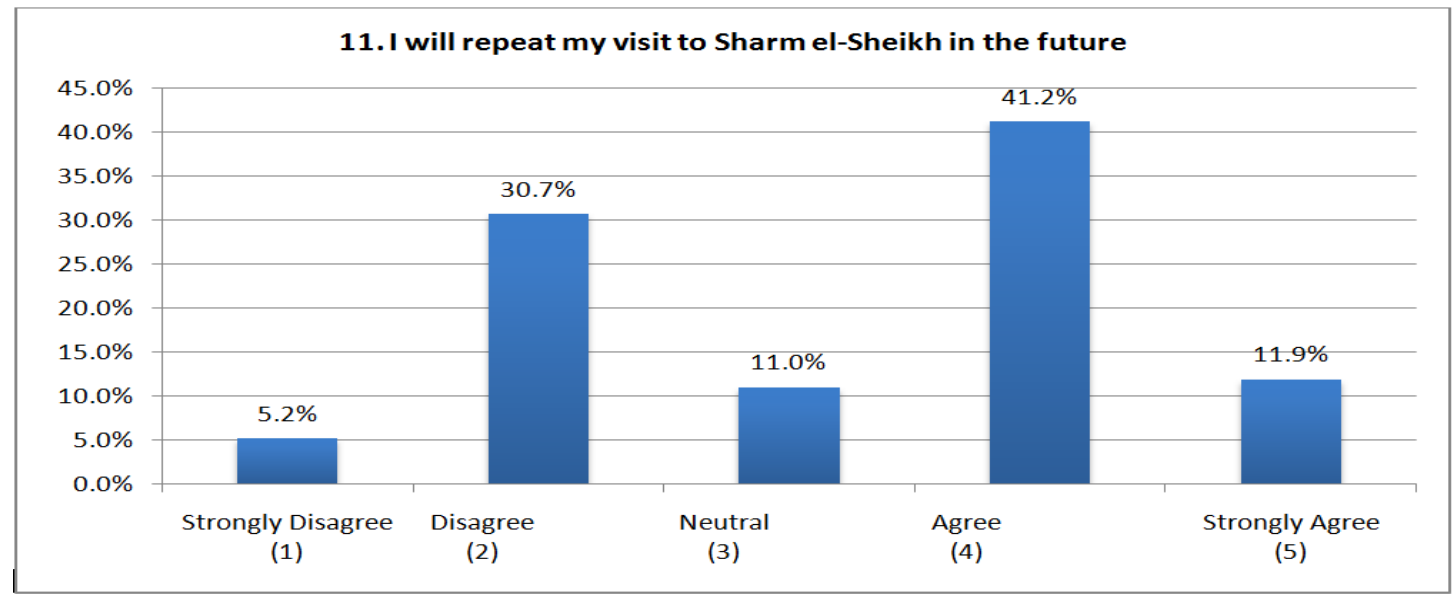


Only the half of the respondents $(53.1 \%)$ agreed that they will repeat the visit to Sharm El-Sheikh in the future, and many respondents $(35.9 \%)$ disagreed with that.

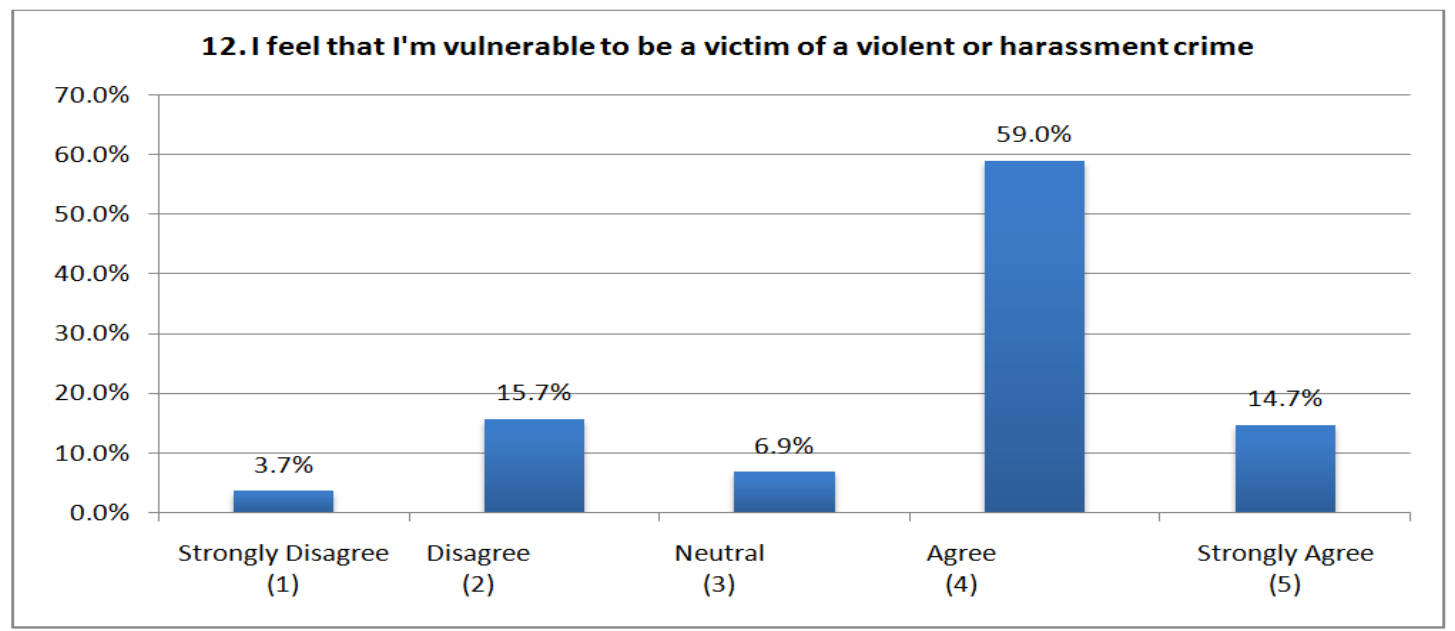

The majority $(73.7 \%)$ agreed that they feel that they are vulnerable to be a victim of a violent or harassment crime.

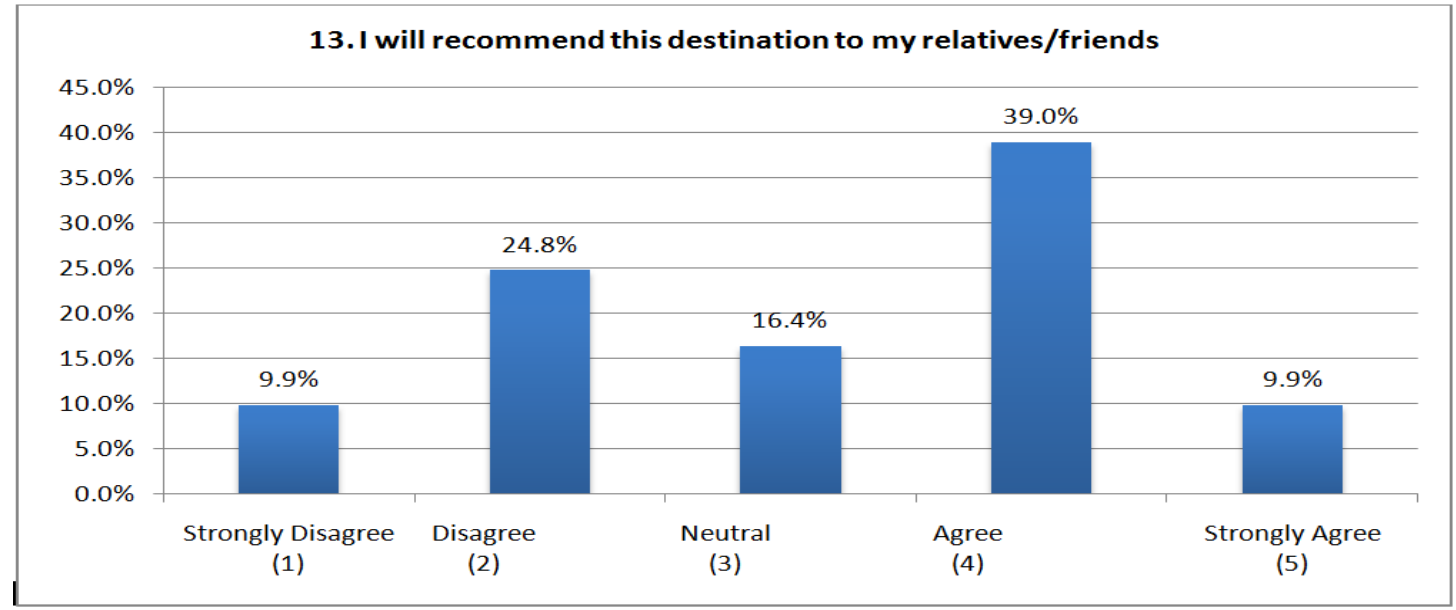

Only (48.9\%) of the respondents agreed that they will recommend Sharm El-Sheikh to their relatives/friends, and many respondents $(37.7 \%)$ disagreed with that. 


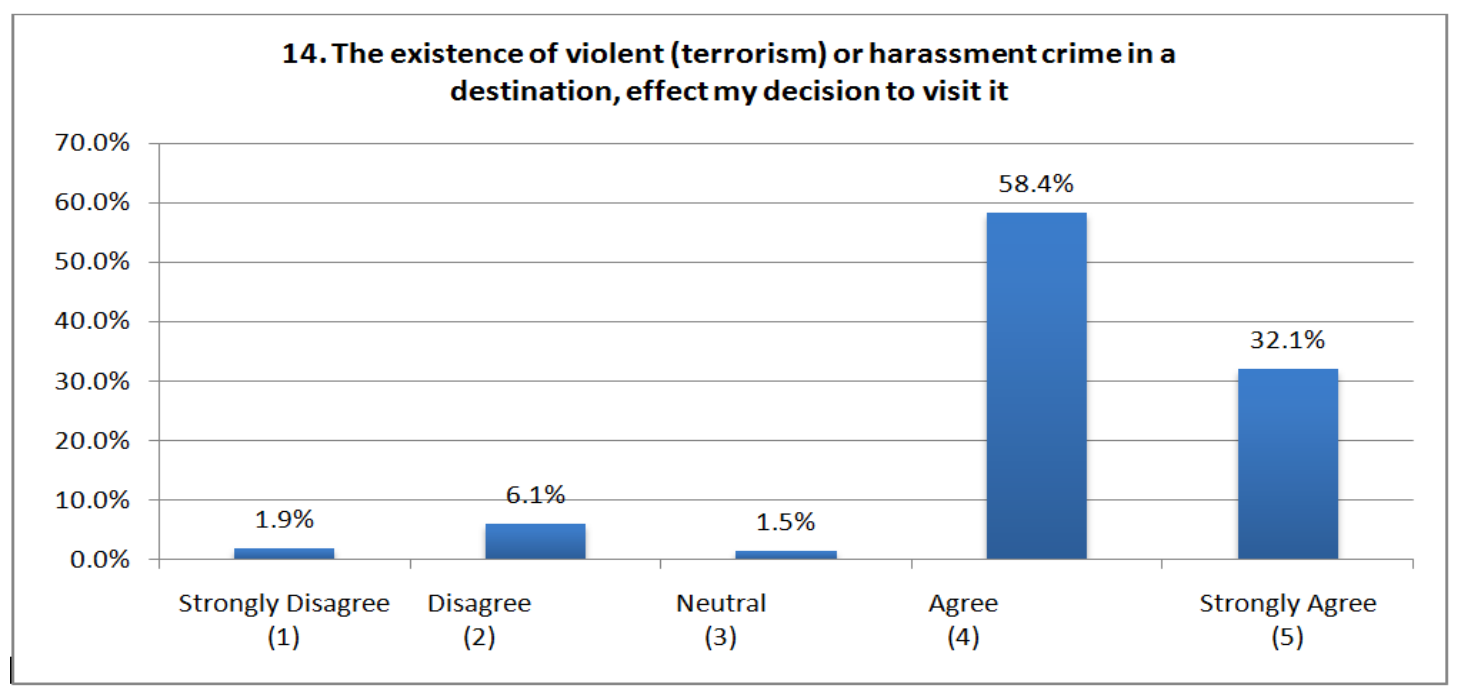

The majority of the respondents $(90.5 \%)$ agreed that the existence of violent or harassment crime in a destination, affect their decision to visit it.

\section{Results and Discussion}

The most important findings were that, the majority of respondents denied that they have been a victim of a violent or harassment crime with (81\%), and that was in conflict with some other responses such as, when the majority of respondents $(73.7 \%)$ agreed that they feel that they are vulnerable to be a victim of a violent or harassment crime. The previous conflict showed that in regard to safety and security of tourists, the perception is a very important factor to be addressed, as the concern of tourists was just a matter of perception and worries and it wasn't base on facts or real situations. Thus, the area of tourist's safety perception must take more care and attention from the decision-makers at any destination in order to maintain a good image for that destination. This point of view is very clear in many responses, as follows:

Only $(58.7 \%)$ agreed that Sharm El-Sheikh as a whole is a safe and secure tourism environment. The majority (84\%) disagreed that in Sharm El-Sheikh, there is a visible presence of police in most tourists' areas. (67\%) of the respondents agreed that in Sharm El-Sheikh, there's a sufficient police station in tourist areas. The majority $(86.6 \%)$ of the respondents disagreed that in Sharm El-Sheikh, it is safe to use the public transportation. $(76.3 \%)$ of the respondents disagreed that in Sharm El-Sheikh, it is safe to visit crowded public areas. (75.9\%) of the respondents disagreed that Sharm El-Sheikh's government is doing its best to ensure the safety of tourists.

Another area that needs to be focused on, is that only half of the respondents $(53.1 \%)$ agreed that they will repeat the visit to Sharm El-Sheikh in the future, and only (48.9\%) of the respondents agreed that they will recommend Sharm El-Sheikh to their relatives/friends, which means that the current image about Sharm El-Sheikh in regard to safety perception is bad and not up to its touristic importance, which proves the $2^{\text {nd }}$ hypothesis of this study (The Image of Sharm El-Sheikh in regard to safety and security is bad). And, since the majority of the respondents (90.5\%) agreed that the existence of violent or harassment crime in a destination, affect their decision to visit it, so the decision-makers of Egyptian tourism industry, have to spare a lot of efforts and pay more 
attention to enhance the safety and security measures, in addition to working with the tourism industry to identify and address crime-related concerns. All the efforts must be combined with an effective legislation framework, but at the same time, we don't have to forget that, although, the Egyptian law includes strict legislation to combat terrorism and the other tourist related crimes, the safety and security in Egypt is still vulnerable, and that leads us to the fact that the problem here is how to activate this legislation to combat terrorism crime and other crimes. Thus, the existence of legislation alone is not enough to fight against crime, and it is necessary to develop some strategies to achieve coordination and integration between all stakeholders concerned to reduce or eliminate the crime. This concept is very clear in the case study of South Africa. Although South Africa is often viewed as the capital crime in the world, it successfully has developed a strategy to achieve tourist safety and security through the cooperation and coordination between all stakeholders, and that can prove the $1^{\text {st }}$ hypothesis of this study (Legislation alone is not enough to maintain safety and security at any tourist destination).

\section{Conclusion}

The focus of the study was to investigate the touristic crimes in the Egyptian legislation. This study concluded that law enforcement responses alone are rarely effective in reducing or solving the touristic crimes problem, therefore, working and co-operating with the tourism industry to identify and address crime-related concerns is required. Police representatives should participate on tourism boards and work with hotel/motel/resorts, convention, and visitors' bureaus to understand tourism-related problems and major concerns, and to develop joint crime prevention programs. All that has the power to enhance the image of Sharm El-Sheikh and whole Egypt as a destination.

\section{Recommendations}

In order to diminish the phenomena of sexual harassment and violence in Egypt, causes of those crimes must be addressed and assessed promptly. In addition, the legal framework, enforcement of the laws and spreading awareness about the issue must be addressed through the roles of the government, parliament, civil society, the different types of media and the public. Last but not least, a collaborative role between government, civil society and media should be implemented. Awareness and educational projects about the importance of tourism industry must be taken in charge in schools, universities, streets, work places and media. Civil society, groups and media have an important role of continually pressuring and monitoring the government and parliament actions and their enforcement of the laws. Moreover, some measurments and efforts must be followed such as:

- Re-establishing the specially-trained tourist police units providing security, safety and assistance to tourists and residents alike.

- Initializing Tourist Hotline for reporting of different crimes against tourists.

- Introduction of " 24 Hours Court" so that cases regarding acts of theft, rape, assaults, harassment and robbery against tourists can be dealt with in a short timeframe.

- Capacity-building for law enforcement and security officials on issues related to crimesand violent acts against tourists, using specialist trainers from overseas; besides training Egytian officers to deal with these acts. 
- Presence of multi-lingual, dedicated "Tourist Relations" police officers in all major police stations.

- Establishing specialized investigation units for tourists' cases.

- Initializing preventive and directed patrols.

- Enhancing greater collaboration between tourism stakeholders, law enforcement agencies and courts.

- Need for mandatory legislated security measures at tourist establishments, resorts and places that cater for tourists.

- Addressing the issues of drug use and youth's maginalization in the Egyptian society.

- Coordinating efforts among tourism stakeholders to prevent tourists from being engaged in any criminal activity.

- Prioritize police investigations and prosecution for tourism-related crimes.

- Educating the public about the importance of the tourism industry, their awareness is extremely important.

\section{References}

1- Baker, D. (2014), The Effects of Terrorism on the Travel and Tourism Industry, International Journal of Religious Tourism and Pilgrimage, Vol. 2: Iss.1, pp62-64.

2- DeAlbuquerque, K., and J. McElroy (1999), Tourism and Crime in the Caribbean, Annals of Tourism Research 26, No.1, pp968-984.

3- Duha T. Altindag (2013), Crime and International Tourism, Journal of Labor Research, December 2013, p1.

4- Ebaid N.(2013), Sexual Harassment in Egypt: A Neglected Crime, An assessment for the Egyptian Government performance in regard to the Sexual Harassment in Egypt, The American University in Cairo, Egypt, pp3-8.

5- Egypt 2014 Crime and Safety Report (2014), Bureau of Diplomatic Security, U.S. Department of State, $13^{\text {th }}$ of March, p1.

6- Harper, D. (2001), Comparing Tourists Crime Victimization, Annals of Tourism Research 28, No.4, pp10531056.

7- Nkosi, G. (2010), The Impact of Crime on Tourism in the City of uMhlathuze, KwaZulu-Natal, South Asian Journal of Tourism and Heritage, Vol. 3, No. 2, pp77,78.

8- Perry,E.C.,Potgieter,C.(2013),Crime and Tourism in South Africa,Journal of Human Ecology,Vol.43,No $1, \mathrm{p} 102$.

9- Pizam, A., Mansfeld, Y. (2005), Towards a Theory of Tourism Security, Elsevier, p4.

10-Ronald W. Glensor, Kenneth J. Pea (2004), Crimes Against Tourists, U.S. Department of Justice, ProblemOriented Guides for Police Problem-Specific Guides Series, No. 26, p3.

11- Schwab, K. (2014), The Global Competitiveness Report 2014-2015, World Economic Forum, Geneva, p38.

\section{Websites}

1- http://jurist.org/paperchase/2014/04/egypt-approves-new-anti-terror-law.php Accessed on: 6/6/2015.

2- http://www.middleeasteye.net/news/sisi-officially-approves-egypt-s-anti-terrorist-law-1284094471 Accessed on: $6 / 6 / 2015$

3- http://www.al-monitor.com/pulse/originals/2015/03/egypt-sisi-anti-terrorism-law-opposition.html\# Accessed on: $6 / 6 / 2015$

4- http://www.restaurant.org.za/pdf/Tourism_Safety_\&_Support_Strat_Framework_WC.pdf . Accessed on: $8 / 6 / 2015$

5- Mozambique's Tourism Law, Law No. 4/2004 of 17 June. Available @ https://www.doingbusiness.org Accessed on: 15/4/2015.

6- Swart, K., Bob, U. and Turco, D.: Media, Crime and the 2010 Soccer World Cup in South Africa: Pre-event Analysis and Perceptions, Available at: http://alternation.ukzn.ac.za/Files/docs/17.2/09\%20Swa\%20FIN.pdf Accessed on: 8/6/2015. 